\title{
The dynamic influence of emotional words on sentence comprehension: An ERP study
}

\author{
Jinfeng Ding ${ }^{1,2} \cdot$ Lin Wang ${ }^{1,3} \cdot$ Yufang Yang ${ }^{1,3}$
}

Published online: 1 February 2016

(C) Psychonomic Society, Inc. 2016

\begin{abstract}
In the present study, we explored the influence of emotional words on the semantic integration of their following neutral nouns during sentence comprehension. We manipulated the emotionality of verbs and the semantic congruity of their following (neutral) object nouns in sentences. Eventrelated potentials were recorded to the verbs, which were either negative or neutral, and to the object nouns, which were either semantically congruent or incongruent relative to the preceding contexts. We found an N400 and a P600 effect in response to the semantic congruity of the nouns when they followed the neutral verbs. However, the P600 (but not the N400) semantic congruity effect may have been attenuated when the nouns followed the negative verbs. Meanwhile, the negative verbs elicited a larger P2 and N400 than did the neutral verbs. The results indicate that the attention captured by emotional words impaired reanalysis of the following incongruent information, demonstrating a dynamic influence of emotional words on the semantic processing of following information during sentence comprehension.
\end{abstract}

Keywords Emotional words - Semantic integration · Sentence comprehension · ERP

Lin Wang

wangl@psych.ac.cn

Yufang Yang

yangyf@psych.ac.cn

1 Key Laboratory of Behavioral Science, Institute of Psychology, Chinese Academy of Sciences, Chaoyang District, Lincui Road 16, Beijing 100101, China

2 University of Chinese Academy of Sciences, Beijing, China

3 Jiangsu Collaborative Innovation Center for Language Ability, Jiangsu Normal University, Xuzhou, China
Traditionally, emotion and cognition are viewed as separate systems that seldom interact (Lyons, 2005). The development of cognitive neuroscience has fostered an interaction/ integration view between emotion and cognition (Blair et al., 2007; Gray, Braver, \& Raichle, 2002; Leventhal \& Scherer, 1987; Pessoa, 2008; Phelps, 2006). On the one hand, cognition, especially social cognition, influences emotional appraisal, learning, and regulation (Ochsner \& Phelps, 2007). On the other hand, emotion influences cognitive functions such as working memory performance (Levens \& Phelps, 2008). Language processing involves the coordination of multiple cognitive processes (including attention and memory retrieval) and is often loaded with emotional information (e.g., emotional words). Therefore, studying how emotional words are processed and exert an influence on other information processing will shed light on our understanding of the interaction between emotion and cognition. In the present study, we examined the influence of emotional words on the semantic processing of following neutral information in sentence contexts.

Behavioral and event-related potential (ERP) studies have suggested that emotional words automatically capture attentional resources. Behavioral evidence has come from studies using dichotic listening, visual search, and emotional Stroop task, as well as tasks that use emotional words as distractors or lures (for a review, see Vuilleumier \& Huang, 2009). In addition, ERP studies have, although inconsistently, shown that emotional words elicit a larger P1 and/or N1 than neutral words (Kissler \& Herbert, 2013; Sass et al., 2010; Wang, Zhu, Bastiaansen, Hagoort, \& Yang, 2013; Zhang et al., 2014; but see Bayer, Sommer, \& Schacht, 2012; Briesemeister, Kuchinke, \& Jacobs, 2014; Fritsch \& Kuchinke, 2013; Hinojosa, Méndez-Bértolo, \& Pozo, 2012; Scott, O’Donnell, Leuthold, \& Sereno, 2009), reflecting automatic allocation of attentional resources to emotional words. Since the early P1 and N1 effects seem to precede lexical- 
semantic access (Dien, 2009), two explanations have been proposed to account for such rapid ERP effects. First, they might be attributed to fast semantic access mediated by a specialized subcortical pathway (LeDoux, 2003; Vuilleumier, 2005). The other explanation is the conditioned association between word form and emotional connotation (Kuchinke, Krause, Fritsch, \& Briesemeister, 2014). In addition to the early ERP effects that reflect automatic attention captured by emotionality, some other emotional ERP effects have also been reported. For instance, as compared to neutral words, emotional words elicit a larger P2 (Herbert, Kissler, Junghöfer, Peyk, \& Rockstroh, 2006; Wang \& Bastiaansen, 2014), early posterior negativity (EPN; Herbert, Junghöfer, \& Kissler, 2008; Kissler, Herbert, Winkler, \& Junghöfer, 2009; Schacht \& Sommer, 2009), and late positive complex (LPC; Carretié et al., 2008; Fischler \& Bradley, 2006; Hinojosa, Méndez-Bértolo, \& Pozo, 2010; Kanske \& Kotz, 2007), probably reflecting greater evaluation of the emotional significance carried by emotional words.

All of the above-mentioned studies focused on the processing of emotional words in isolation. Other studies have examined the processing of emotional words in sentence or discourse contexts. For instance, Holt, Lynn, and Kuperberg (2009), as well as Ding, Wang, and Yang (2015), found that emotional words elicited larger N400s than neutral words when the words were integrated into neutral sentence contexts under a passive-reading task. Generally, the N400 amplitude relates to the difficulty of integrating a stimulus into the mental representation of context (Brown \& Hagoort, 1993; Kutas $\&$ Federmeier, 2011). Holt et al. proposed two possibilities for the emotional N400 effect found in sentence contexts. One possibility is that emotional and neutral words are represented in distinct neural networks. Thus, the integration of emotional words into a neutral context would be more demanding than the integration of neutral words into a neutral context. Another possibility is that the emotional words could attract more attentional resources, and in turn that additional processing resources would be available for more detailed semantic analysis. However, Wang, Bastiaansen, Yang, and Hagoort (2013) found a smaller N400 for positive than for negative and neutral words, indicating that the semantic integration of positive words was facilitated by the fact that healthy people tend to expect positive information more than negative information. In addition, studies manipulating the congruity of emotional words relative to the preceding context reported interesting results. For instance, smaller (if any) N400 effects in response to semantic congruity were reported for emotional words than for solely semantically incongruent neutral words (Delaney-Busch \& Kuperberg, 2013; Moreno \& Vázquez, 2011), suggesting that the affective primacy of emotional words might block further semantic analysis of the emotional words. In addition, larger LPCs were also reported in response to emotional relative to neutral words (Delaney-Busch \& Kuperberg, 2013; Holt et al., 2009), reflecting reallocation of attentional resources to emotional information (Hajcak, Weinberg, MacNamara, \& Foti, 2012). Taken together, the prioritized processing of emotional words can be manifested by enhanced perceptual processing (as indicated by the early $\mathrm{P} 1 / \mathrm{N} 1$ effects), more detailed semantic analysis (as indicated by the larger $\mathrm{N} 400$ ), and more elaborative emotional evaluation (as indicated by the LPC effect), as compared to neutral words.

Investigating the processing of neutral words in an emotional context would allow us to further characterize the influence of emotion on cognitive processing. So far, several studies have attempted to use single words (Fischler \& Bradley, 2006; Hinojosa et al., 2012), sentence frames (Ding et al., 2015; Moreno \& Vázquez, 2011), and paragraphs (Jiménez-Ortega et al., 2012) to set up emotional context and have examined how the emotional context modulates the analysis of different levels of upcoming neutral information. For instance, Hinojosa et al. (2012) reported larger N1 and LPC amplitudes in response to neutral words primed by high-arousal rather than by low-arousal positive words in the lexical-decision task, indicating potentiated perceptual processing and enhanced postlexical analyses of neutral information following high-arousal information. However, when asking participants to judge the coherence of adjective-noun word pairs in which the emotionality of the two words was manipulated (pleasant, neutral, and unpleasant), Fischler and Bradley found no emotional effect of the adjectives on the brain responses to the nouns. The results reflect no effect of emotional words on the semantic integration of subsequent neutral words with preceding words. Recently, Ding et al. reported P2 and N400 effects in response to the orthographic correctness of neutral nouns when they followed neutral verbs in sentences, whereas only an LPC effect was observed when the nouns followed emotional verbs. Therefore, the emotionality of words modulates at least the perceptual analysis, and potentially the semantic integration, of the following words. To further examine the influence of emotion on the semantic analysis of following words, Moreno and Vázquez (2011) and Jiménez-Ortega et al. (2012) manipulated the semantic congruence of critical words following positive/negative sentence frames and emotional/neutral paragraphs, respectively. They found the same ERP effects (i.e., an N400 effect and N400 P600 effects, respectively) in response to semantic congruity in differently valenced contexts. It seems that emotion has no effect on the semantic integration of neutral information into a preceding emotional context. Nevertheless, Jiménez-Ortega et al. found that the syntactically violating words, relative to correct words, elicited a larger LAN and P600 in the positive and negative contexts, but only a larger P600 in the neutral context, reflecting a modulation of emotional context on the syntactic processing of the critical words. A P600 effect has 
been reported in response to orthographic, semantic, and syntactic correctness. This was taken as a reflection of general reanalysis of the inputs (Szewczyk \& Schriefers, 2011; Vissers, Chwilla, \& Kolk, 2006).

The above-mentioned studies revealed inconsistent effects of emotion on the analysis of different levels of upcoming neutral information. The enhancement effect could be explained by priority-binding theory (MacKay et al., 2004), in which emotion-linked stimuli (i.e., the neutral information bound with the emotional information) are given processing priority. Therefore, the perceptual and postlexical processing of neutral information were enhanced in an emotional context (Hinojosa et al., 2012). On the contrary, the impairment effect could be explained by attention-narrowing hypothesis (Christianson, 1992; Easterbrook, 1959), which proposes that emotional information captures more attentional resources, implying impaired processing of upcoming neutral information and resulting in impaired perceptual analysis and lexicosemantic processing of subsequent neutral information (Ding et al., 2015). It should be noted that priority-binding theory and the attention-narrowing hypothesis were originally used to interpret the results of emotional memory studies. These studies investigated the influence of emotional information on the memory of concurrent/following neutral information and revealed enhancement or impairment effects. For instance, the priority-binding theory explains better memory of neutral words embedded in emotional than in neutral sentences (Brierley, Medford, Shaw, \& David, 2007; Guillet $\&$ Arndt, 2009), whereas the attention-narrowing hypothesis explains reduced report accuracy or recall of neutral words cooccurring with taboo words, as compared to neutral words with other neutral words (Hadley \& MacKay, 2006; MacKay et al., 2004; Mathewson, Arnell, \& Mansfield, 2008). Given that the memory trace relates to the depth of information analysis (Craik \& Lockhart, 1972; Craik \& Tulving, 1975), these theories could be used to explain the influence of emotional information on the online processing of the accompanied neutral information.

Taken together, existing studies suggest that emotional context modulates different levels of following-information processing. However, mixed results were reported regarding the influence of emotional information on the semantic integration of following information. The discrepancies could be attributed to the ways of inducing emotional context (e.g., Moreno \& Vázquez, 2011 [sentence frames], vs. JiménezOrtega et al., 2012 [paragraphs]), the task demands of the studies (e.g., Fishler \& Bradley, 2006 [coherence decision], vs. Ding et al., 2015 [reading for comprehension]), or sentence constraints (e.g., Moreno \& Vázquez, 2011 [high], vs. Ding et al., 2015 [low]). In the present study, we aimed to further examine the influence of emotional words on the semantic integration of neutral words in the same argument structure during sentence comprehension. We manipulated the emotionality of the verbs and the semantic congruity of the following object nouns. In the present study, we used negative verbs to induce emotion (e.g., "steal" vs. "unload") because our previous study (Ding et al., 2015) had seemed to indicate that the negative words had a stronger modulation on processing of the following words than did the positive words. In addition, semantic congruity was manipulated by varying the fit between the object nouns and the introductory contexts prior to the verbs. For example, "steal steel" and "unload steel" fit with the context "on the construction site," whereas "steal tomatoes" and "unload tomatoes" did not fit.

When the semantic incongruity occurred in the neutral context, we expected a larger N400 for the semantically incongruent than for the congruent nouns, because they would be more difficult to integrate into prior contexts (for a review, see Kutas \& Federmeier, 2011). According to the attentionnarrowing theory, the preceding negative verbs would capture and hold attentional resources, leading to limited attentional resources being devoted to the following neutral words. If this is the case, two scenarios might be envisaged. First, the initial semantic analysis of the following words might be impaired, resulting in a smaller (if any) N400 effect in the negative context. Second, the attention captured by the preceding negative verbs might only affect the semantic reanalysis of the following words, leading to an equally large N400 effect. By contrast, according to the priority-binding theory, nouns following negative verbs will be given processing priority, so that adequate processing resources will be allocated to the nouns for semantic analysis, resulting in a larger N400 effect than in the neutral context. In addition to the N400 effect, a P600 effect has been reported in response to semantic congruity (Jimenez-Ortega et al., 2012; Kuperberg, Kreher, Sitnikova, Caplan, \& Holcomb, 2007; Nieuwland \& Van Berkum, 2005), probably reflecting a general reanalysis of the inputs (Szewczyk \& Schriefers, 2011). Therefore, we would expect a larger P600 in the semantically incongruent than in the congruent condition when sufficient processing resources are available for semantic reanalysis in the neutral context. However, in the negative context, the attentionnarrowing hypothesis might lead to two possibilities. First, if the attention attracted by the preceding negative verbs disrupted the initial semantic analysis of the nouns, a P600 effect (instead of an $\mathrm{N} 400$ effect) would be elicited in response to the semantic congruity. Second, the attentional capture of the preceding negative verbs might be too subtle to affect the initial semantic analysis, given the automaticity of the N400 (Kutas \& Federmeier, 2011), and therefore only the semantic reanalysis of the nouns might be affected, leading to the absence of a P600 effect in the negative context. In contrast, the priority-binding theory predicts that more processing resources would be allocated to the nouns following emotional verbs, so the semantic incongruity would elicit an amplified P600 effect in the negative as compared to the neutral context. 
Moreover, we would expect the negative verbs to elicit early (such as N1/P2) and late (such as N400/LPC) ERP effects, due to automatic allocation of attention to the emotional words and the difficulty for semantic processing of the emotional words in neutral contexts.

\section{Method}

\section{Participants}

Thirty university students (mean age 22 years, range 18-26; 15 females, 15 males) participated in the experiment. All of the participants were right-handed native Chinese speakers. They reported no dyslexia or neural impairment and had normal or corrected-to-normal visual acuity. They read and signed a written consent form before taking part in the experiment. The data of four participants (two females, two males) were excluded due to extensive artifacts. The final analysis was performed on the data from 26 participants (mean age 21 years, range 19-26; 13 females, 13 males).

\section{Materials}

We constructed 180 items, with each of them being presented in four conditions. All of the sentences had a similar structure: introductory context + critical verb + critical noun + others. We manipulated the emotionality of the critical verb and the semantic congruity between the critical noun and the introductory context. Therefore, each item was shown in four conditions: emotional verb-congruent noun, emotional verb-incongruent noun, neutral verb-congruent noun, and neutral verbincongruent noun. Table 1 presents an example of the stimuli. In order to balance the emotional valence of all of the experimental stimuli, we also selected some positive verbs as filler items. Altogether, there were 180 emotional verbs (106 negative, 74 positive), 180 corresponding neutral verbs, and 360 following neutral nouns. The positive fillers were used in both the rating pretests and the main ERP experiment.

Fifteen participants (mean age 23 years, range 20-28; eight females, seven males) rated all of the words for valence and arousal, and another 15 participants (mean age 23 years, range 20-29; 12 females, three males) rated all of the words for concreteness using 7-point Likert scales (7 indicating the most positive, most arousing, and most concrete). Furthermore, the verbs and nouns were controlled for word frequency, which is the log transform of the total number of times that the word appears in film subtitles (46.8 million characters in total; Cai $\&$ Brysbaert, 2010). In addition, all of the critical words (verbs and nouns) were two-Chinese-character compound words that were controlled for number of strokes. On the basis of the rating results, we deleted 24 items (ten negative, 14 positive) for which the emotional and neutral verbs or the semantically
Table 1 Examples of the stimuli

Emotional congruent

夜里有人在工地盗窃钢筋吵醒了居民。

At night someone on the construction site stole steel and wakened the residents.

Someone stole steel from the construction site at night and wakened the residents.

Emotional incongruent

夜里有人在工地盗窃番茄吵醒了居民。

At night someone on the construction site stole tomatoes and wakened the residents.

Someone stole tomatoes from the construction site at night and wakened the residents.

Neutral congruent

夜里有人在工地卸载钢筋吵醒了居民。

At night someone on the construction site unloaded steel and wakened the residents.

Someone unloaded steel from the construction site at night and wakened the residents.

Neutral incongruent

夜里有人在工地卸载番茄吵醒了居民。

At night someone on the construction site unloaded tomatoes and wakened the residents.

Someone unloaded tomatoes on the construction site at night and wakened the residents.

The examples were originally in Chinese and are followed by literal translations and paraphrases. The critical verbs are in boldface, and the critical nouns are underlined.

congruent and incongruent nouns showed large differences in concreteness.

The remaining 156 items (96 negative, 60 positive) were divided into four versions using a Latin-square design. Each version did not include sentences in different conditions for the same item. Then 24 participants (different from those who participated in the EEG study; mean age 23 years, range 20 29; 11 females, 13 males) rated the sentences for plausibility using a 7-point Likert scale (7 indicates the most plausible). In order to match the semantic congruity difference between the emotional and neutral contexts, 12 items (eight negative, four positive) were deleted. Finally, 144 items (88 negative, 56 positive) were kept for the main ERP experiment. The negative items were selected as critical stimuli, and the positive items served as fillers.

Table 2 presents the rating results for the critical words (including only 88 negative and 88 neutral verbs, as well as 176 nouns). Statistical analysis revealed that the negative and neutral verbs were significantly different in valence $[t(87)=$ $18.73, p<.001]$ and arousal $[t(87)=19.43, p<.001]$, but not in concreteness $[t(87)=0.76, p=.449]$, word frequency $[t(53)$ $=-0.67, p=.505]$, and number of strokes $[t(87)=1.60, p=$ .113]. Also, the congruent nouns were matched with the incongruent nouns in all variables $[t(87)=0.01, p=.989 ; t(87)=$ 
Table 2 Means (and $S D$ s) of the variables for critical verbs and nouns in the pretests

\begin{tabular}{|c|c|c|c|c|c|c|}
\hline & Valence & Arousal & Concreteness & $\begin{array}{l}\text { Word } \\
\text { Frequency }\end{array}$ & $\begin{array}{l}\text { Cloze } \\
\text { Probability }\end{array}$ & Strokes \\
\hline Negative verbs & $\begin{array}{l}2.58 \\
\quad(0.59)\end{array}$ & $\begin{array}{l}4.54 \\
\quad(0.63)\end{array}$ & $4.23(0.35)$ & $2.42(0.56)$ & $\begin{array}{l}0.23 \% \\
\quad(1.22 \%)\end{array}$ & $\begin{array}{l}18.59 \\
(4.83)\end{array}$ \\
\hline Neutral verbs & $\begin{array}{l}4.12 \\
\quad(0.37)\end{array}$ & $\begin{array}{l}3.02 \\
\quad(0.42)\end{array}$ & $4.19(0.38)$ & $2.51(0.91)$ & $\begin{array}{l}0.15 \% \\
\quad(1.42 \%)\end{array}$ & $\begin{array}{l}17.64 \\
(3.88)\end{array}$ \\
\hline $\begin{array}{c}\text { Congruent } \\
\text { nouns }\end{array}$ & $\begin{array}{l}4.17 \\
\quad(0.40)\end{array}$ & $\begin{array}{l}3.03 \\
\quad(0.51)\end{array}$ & $5.54(0.66)$ & $2.37(0.77)$ & $\begin{array}{l}3.98 \% \\
(11.30 \%) \\
2.98 \% \\
(9.28 \%)\end{array}$ & $\begin{array}{l}17.07 \\
(4.37)\end{array}$ \\
\hline $\begin{array}{l}\text { Incongruent } \\
\text { nouns }\end{array}$ & $\begin{array}{l}4.17 \\
\quad(0.39)\end{array}$ & $\begin{array}{l}2.96 \\
\quad(0.45)\end{array}$ & $5.59(0.71)$ & $2.24(0.86)$ & 0 & $\begin{array}{l}16.43 \\
(3.92)\end{array}$ \\
\hline
\end{tabular}

$S D$, standard deviation. The rating results were obtained for 88 negative and 88 neutral verbs, as well as 88 congruent and 88 incongruent nouns. The two numbers, $3.98 \%(11.30 \%)$ and $2.98 \%(9.28 \%)$, in the same cell represent the cloze probabilities for congruent nouns in the emotional and neutral contexts, respectively.

$1.18, p=.243 ; t(87)=-0.77, p=.442 ; t(53)=1.06, p=.293$ and $t(87)=1.14, p=.258$, respectively, for valence, arousal, concreteness, word frequency, and number of strokes]. Moreover, the congruent sentences were rated as being more plausible than the incongruent sentences $[F(1,87)=425.94, p$ $\left.<.001, \eta_{\mathrm{p}}{ }^{2}=.830\right]$, whereas no plausibility difference was found between the negative and neutral contexts $[F(1,87)=$ $\left.1.63, p=.206, \eta_{\mathrm{p}}{ }^{2}=.018\right]$. Neither was there any interaction between emotionality and semantic congruity in plausibility $\left[F(1,87)=2.24, p=.138, \eta_{\mathrm{p}}{ }^{2}=.025\right]$.

Moreover, we measured the cloze probabilities of the critical words. For the critical verbs, we asked 15 participants (mean age 22 years, range 20-25; seven females, eight males) to complete the sentence fragments that were presented prior to the critical verbs. For the critical nouns, we instructed 16 participants (mean age 23 years, range 19-29; ten females, six males) to continue the sentences, which were presented up until the critical nouns. The same sentence frames containing negative and neutral verbs were divided into two lists, and each participant was only assigned to one list. The cloze probabilities for the negative and neutral verbs did not reach significance $[t(87)=0.38, p=.708]$. Also, the semantically congruent nouns showed equally low cloze probabilities between the negative and neutral contexts $[t(87)=0.80, p=.428]$. Since the semantically incongruent words were not expected, the cloze probabilities of the incongruent nouns were zero in both the negative and neutral sentence frames. In addition, the constraints of the negative and neutral sentences were not significantly different [the cloze probabilities of the most commonly reported continuations were mean $(S D)=26.28 \%$ $(16.85 \%)$ and $27.41 \%(15.15 \%)$, respectively, for the negative and neutral sentences, $t(87)=-0.49, p=.624]$.

Finally, we used a Latin-square design to divide the 88 critical negative items (four sentences for each item) and the 56 positive filler items into four versions, with no repetition of items within the same version. Each version contained 88 experimental sentences ( 22 sentences in each condition) and
56 filler sentences (14 sentences in each condition). Additionally, we added another set of 48 fillers that had relatively flexible sentence structures. In order to vary the positions of the semantically incongruent nouns, half of the fillers contained semantic incongruity in positions different from the experimental stimuli. The other half contained no semantic incongruity. Overall, each version of the experiment contained 192 sentences, with 88 critical items and 104 fillers.

\section{Procedure}

Participants were randomly assigned to one of the four versions. The 192 sentences in one version were presented in a pseudo-random order, with no more than three sentences of the same condition presented in succession. All words were shown in white color on a black background, with a font size of 40 in Song typeface. Each trial began with a 300-ms fixation cross in the center of the screen, followed by a $200-\mathrm{ms}$ blank screen. Then a sentence was presented word by word. Each word was presented for $300 \mathrm{~ms}$ with a blank screen of $200 \mathrm{~ms}$ between each two words. Then, 1,000 ms after the presentation of the last word, the next trial began. In order to ensure that participants had read and comprehended the sentences carefully, we told them that there would be a comprehension test covering the sentences after the experiment.

The 192 sentences in each version were evenly divided into four blocks, with each block lasting about $5 \mathrm{~min}$. There was a 3 min break between each two blocks. The whole experiment took about one and a half hours, including participants' preparation, the instructions, and a practice of 16 trials.

\section{Electroencephalogram (EEG) recording and preprocessing}

EEG was recorded using AC amplifiers. A total of $64 \mathrm{Ag}-$ $\mathrm{AgCl}$ electrodes were placed according to the standard International 10-20 System locations on an elastic cap, with 
a sampling rate of $500 \mathrm{~Hz}$ and a band-pass filter of 0.05 $100 \mathrm{~Hz}$. The electrooculograms (EOGs) were recorded at electrodes placed above and below the left eye and lateral to the outer canthus of each eye, to monitor vertical and horizontal eye blinks and movements. EEG data were referenced online to the right mastoid, and all electrodes impendences were kept below $5 \mathrm{k} \Omega$. An electrode localized between the Fpz and Fz electrodes served as the ground.

The EEG data were analyzed with Neuroscan 4.3 offline (Neuroscan, 2003). We rejected apparent large artifacts on the basis of visual inspection of the EEG signals. Then, after automatically correcting eye blinks (Semlitsch, Anderer, Schuster, \& Presslich, 1986), the EEG signal was filtered using a band-pass filter at $0.1-30 \mathrm{~Hz}(24 \mathrm{~dB} /$ oct slope, halfpower cutoff). In order to maximally examine the influence of the emotional verbs, the EEG data were segmented into epochs of 1,200 ms for critical verbs and of $1,700 \mathrm{~ms}$ for critical nouns, both starting $200 \mathrm{~ms}$ prior to the onset of the critical words, so that the epochs of the critical verbs covered both the critical verbs and the critical nouns, whereas the epochs of the critical nouns covered both the critical nouns and their following two words (which was the minimum number of words after the critical nouns in all sentences). The mean amplitude in the 200-ms prestimulus interval served as baseline, and epochs exceeding $\pm 80 \mu \mathrm{V}$ at any EEG electrode were rejected from the averaging. Then, the ERPs were rereferenced offline to the algebraic average of two mastoids. Finally, grand average ERPs were calculated for each participant at each electrode in each condition.

\section{ERP data analysis}

On the basis of both visual inspection and previous studies (Dambacher et al., 2012; Ding et al., 2015; Wang, Bastiaansen, et al., 2013), the following time windows were selected for the critical nouns: $90-140 \mathrm{~ms}(\mathrm{~N} 1), 170-240 \mathrm{~ms}$ (P2), 300-470 ms (N400), 500-800 ms (early P600), and $800-1,500$ ms (late P600). For the critical verbs, we chose the following time windows to statistically analyze the emotional effects: $170-240 \mathrm{~ms}$ (P2), 300-500 ms (N400), and 500-800 ms (LPC). For the critical nouns, repeated measures analyses of variance (ANOVAs) were conducted with Emotionality (negative, neutral), Semantic Congruity (congruent, incongruent), Laterality (left, midline, right), and Anteriority (anterior, central, posterior) as within-subjects factors. Due to a possible baseline difference between the negative and neutral contexts for the critical nouns (the nouns were presented $500 \mathrm{~ms}$ after the verbs' onsets), we only report the main effect of semantic congruity and the interaction between emotionality and semantic congruity (or with laterality/ anteriority). For the critical verbs, emotionality (negative, neutral) and topographic factors (laterality and anteriority) served as within-subjects variables. Figure 1 presents the selected electrodes and the division. Any significant interactions with semantic congruity and emotionality were followed by simple-effects tests. Greenhouse-Geisser correction was applied when appropriate (Greenhouse \& Geisser, 1959), and the original degrees of freedom are reported with corrected $p$ values.

\section{Results}

Figures 2 and 3 present the average amplitudes elicited by the critical nouns in the neutral and negative contexts, respectively, at nine selected electrodes $(\mathrm{F} 3 / \mathrm{C} 3 / \mathrm{P} 3, \mathrm{Fz} / \mathrm{Cz} / \mathrm{Pz}$, and $\mathrm{F} 4 /$ $\mathrm{C} 4 / \mathrm{P} 4$, surrounded by thick circles in Fig. 1). Figure 4 presents the grand average waveforms for the critical verbs. Because our study focused on the influence of negative words on the semantic processing of their following neutral words, we first report the results for the critical nouns, and then those for the critical verbs.

\section{Semantic congruity effects}

In the time windows of $90-140$ and $170-240 \mathrm{~ms}$, we did not find any significant main effect of or interaction with the critical manipulations (emotionality and semantic congruity).

In the time window of 300-470 ms, the main effect of semantic congruity was significant $\left[F(1,25)=11.16, p=.003, \eta_{\mathrm{p}}{ }^{2}\right.$ $=.309]$, showing that the semantically incongruent nouns

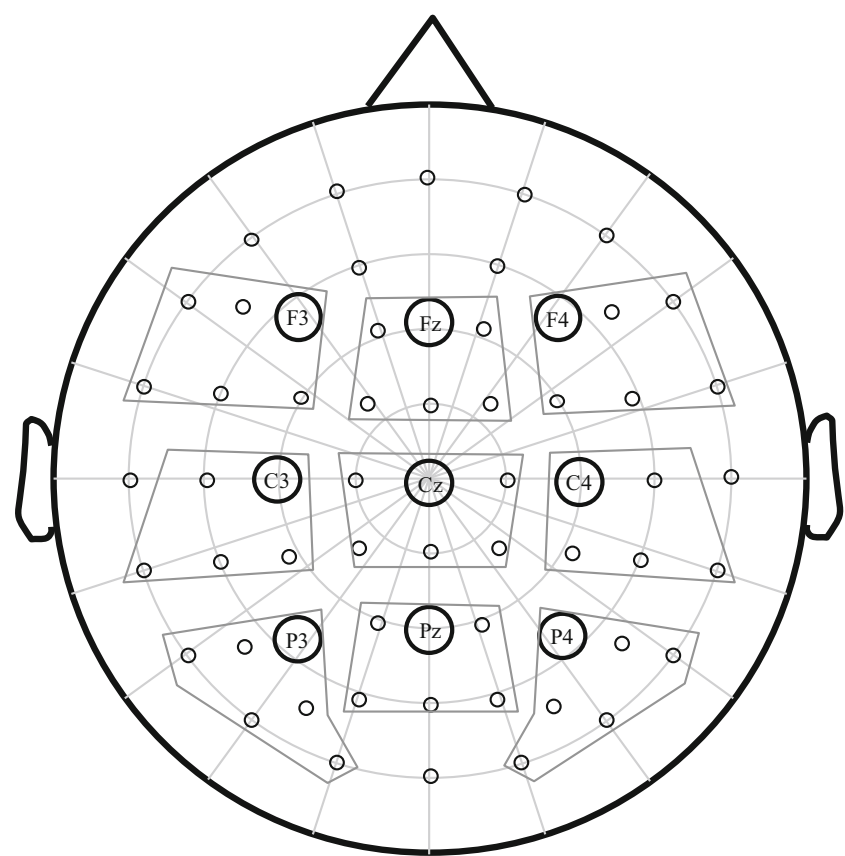

Fig. 1 Electrode layout on the scalp. The electrodes selected for analysis were grouped into nine regions, and the nine representative electrodes chosen for displaying the grand average waveforms are encircled with thicker lines 
A

ERP waveforms showing the semantic congruity effects in the neutral contexts.

F3

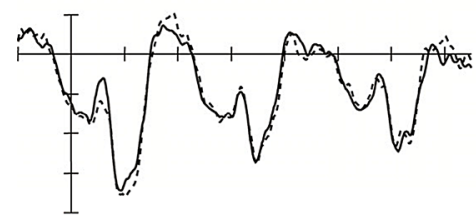

C3

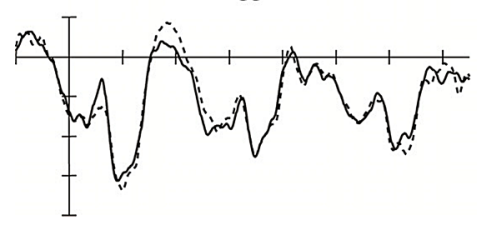

P3

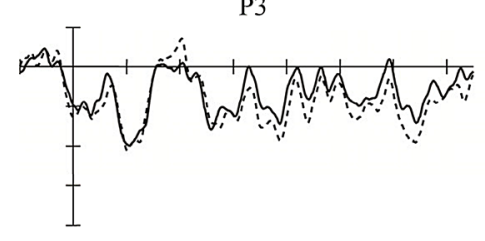

B
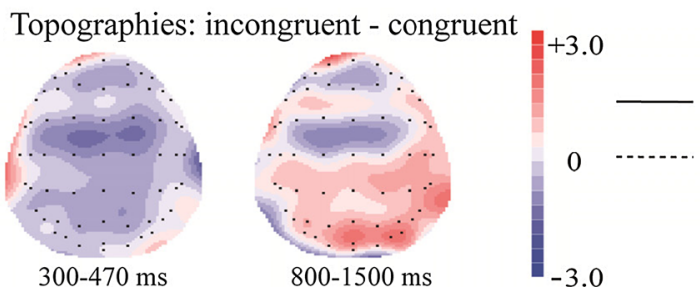

Fig. 2 Semantic congruity effects of the critical nouns in the neutral contexts. (a) Grand averaged waveforms evoked by the critical nouns in the neutral contexts at nine representative electrodes. The solid lines represent semantically congruent words, and the dotted lines represent

elicited a larger N400 than did the congruent nouns. However, the interaction between emotionality and semantic congruity (or with the topographic factors) was not significant. We found a significant interaction between semantic congruity and laterality $\left[F(2,50)=3.35, p=.043, \eta_{\mathrm{p}}{ }^{2}=.118\right]$. Simple-effects tests revealed significant effects of semantic congruity over the left $\left[F(1,25)=7.79, p=.010, \eta_{\mathrm{p}}{ }^{2}=.238\right]$, midline $[F(1,25)=$ $\left.12.18, p=.002, \eta_{\mathrm{p}}{ }^{2}=.328\right]$, and right $[F(1,25)=8.71, p=$ $\left..007, \eta_{\mathrm{p}}{ }^{2}=.258\right]$ regions.

In the time window of 500-800 ms, no significant main effect of semantic congruity emerged, or any other interaction with it. In the time window of $800-1,500 \mathrm{~ms}$, we found a marginally significant interaction of emotionality, semantic congruity, and anteriority $\left[F(2,50)=8.62, p=.058, \eta_{\mathrm{p}}^{2}=\right.$ .111]. Then we performed three two-way (Emotionality $x$ Semantic Congruity) ANOVAs over the anterior, central, and posterior regions. The interaction between emotionality and semantic congruity was not significant over the anterior $\left[F(1,25)=0.001, p=.973, \eta_{\mathrm{p}}{ }^{2} \leq .001\right]$, central $[F(1,25)=$ $\left.0.33, p=.571, \eta_{\mathrm{p}}{ }^{2}=.013\right]$, or posterior $[F(1,25)=3.47, p=$
$\mathrm{Fz}$

F4

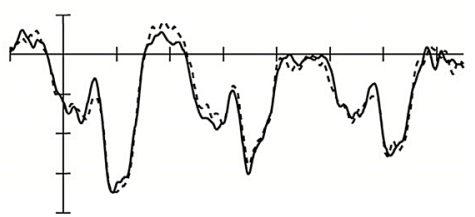

C.4

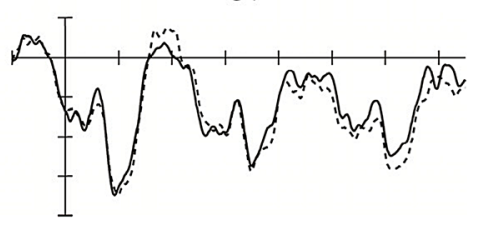

P4

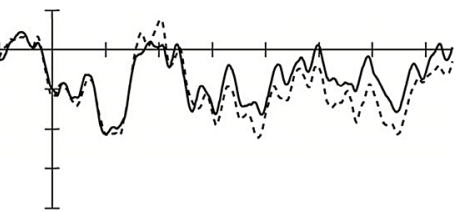

congruent

incongruent

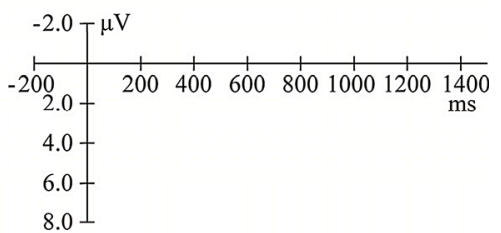

semantically incongruent words. (b) Topographies showing the average amplitude voltage differences between the semantically incongruent and congruent words

$\left..074, \eta_{\mathrm{p}}{ }^{2}=.122\right]$ regions. Though a generalizable interaction might be difficult to infer $(p=.074)$ over the posterior region, visual inspection of the waveforms shows a clear effect for the neutral nouns when they followed the neutral verbs (as is shown in Fig. 2a), but not when they followed the negative verbs (as is shown in Fig. 3a). Further analyses over the posterior region showed that the semantically incongruent nouns elicited a larger P600 than did the congruent nouns in the neutral context $\left[F(1,25)=4.57, p=.043, \eta_{\mathrm{p}}{ }^{2}=.154\right]$, but not in the negative context $\left[F(1,25)=0.52, p=.478, \eta_{\mathrm{p}}{ }^{2}=\right.$ .020].

Overall, the semantically incongruent nouns elicited larger N400 amplitudes with broad distributions and larger P600 amplitudes over the posterior region than the semantically congruent nouns in the neutral context (as is shown in the scalp topographies in Fig. 2b). In the negative context, the semantically incongruent nouns only elicited a larger N400 than the congruent nouns over broad regions (as is shown in the scalp topography in Fig. 3b). 
A ERP waveforms showing the semantic congruity effect in the negative contexts.

F3

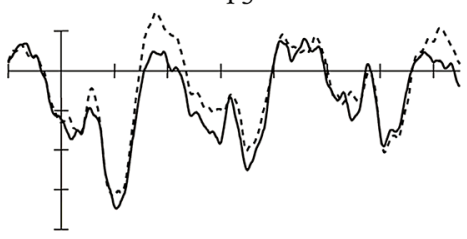

C3

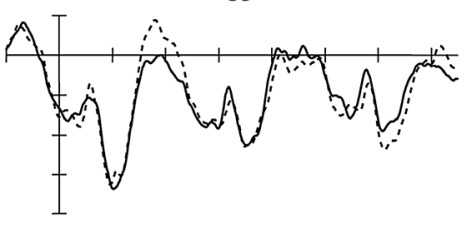

P3

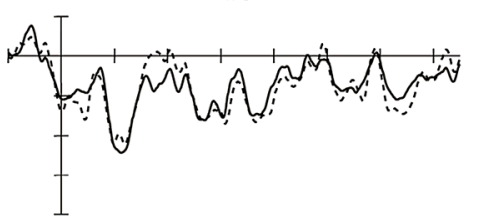

$\mathrm{B}$

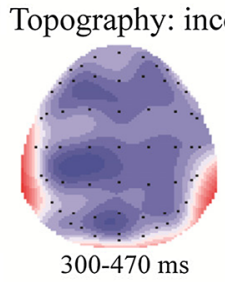

Fig. 3 Semantic congruity effect of the critical nouns in the negative contexts. (a) Grand averaged waveforms evoked by the critical nouns in the negative contexts at nine representative electrodes. The solid lines represent semantically congruent nouns, and the dotted lines represent

\section{Emotionality effects of verbs}

In the time window of 170-240 ms, we observed a significant interaction between emotionality and laterality $\left[F(2,50)=5.84, p=.005, \eta_{\mathrm{p}}{ }^{2}=.189\right]$, as well as a significant interaction between emotionality and anteriority $\left[F(2,50)=14.75, p<.001, \eta_{\mathrm{p}}{ }^{2}=.371\right]$. Simple-effects tests revealed that the negative verbs elicited enhanced P2 amplitudes relative to the neutral verbs over the midline $\left[F(1,25)=3.87, p=.060, \eta_{\mathrm{p}}{ }^{2}=.134\right]$ and anterior $\left[F(1,25)=9.67, p=.005, \eta_{\mathrm{p}}{ }^{2}=.279\right]$ regions. No P2 effect was found over left $[F(1,25)=1.90$, $\left.p=.180, \eta_{\mathrm{p}}{ }^{2}=.071\right]$ and right $[F(1,25)=0.003, p=$ $\left..959, \eta_{\mathrm{p}}{ }^{2}<.001\right]$ regions, or over central $[F(1,25)=2.64$, $\left.p=.117, \eta_{\mathrm{p}}{ }^{2}=.095\right]$ and posterior $[F(1,25)=2.55, p=$ $\left..125, \eta^{2}=.093\right]$ regions.

In the time window of $300-500 \mathrm{~ms}$, the negative verbs elicited larger N400 amplitudes than the neutral verbs [main effect of emotionality: $\left.F(1,25)=8.71, p=.007, \eta_{\mathrm{p}}{ }^{2}=.258\right]$. No significant interaction with emotionality was obtained.
$\mathrm{Fz}$

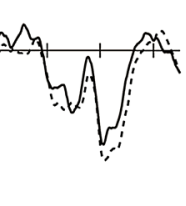

$\mathrm{Cz}$

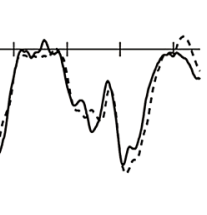

$\mathrm{Pz}$

$\mathrm{N} 400$

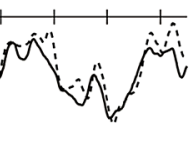

F4

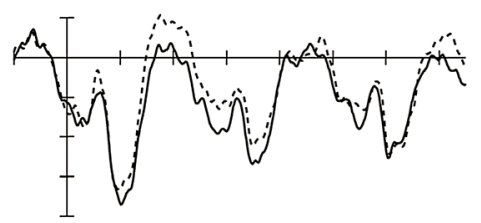

C4

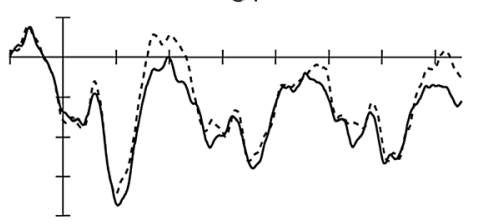

P4

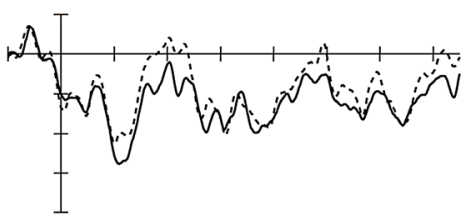

congruent

incongruent

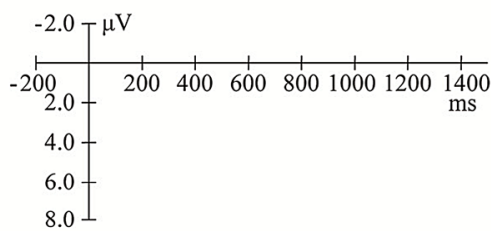

semantically incongruent nouns. (b) Topography showing the average amplitude voltage differences between the semantically incongruent and congruent words

In the time window of $500-800 \mathrm{~ms}$, the negative verbs elicited smaller late positivities than did the neutral verbs [main effect of emotionality: $F(1,25)=4.37, p=.047, \eta_{\mathrm{p}}{ }^{2}=$ .149]. However, we did not find any significant interaction with emotionality.

Overall, the negative verbs yielded a larger P2 over the midline and anterior regions, as well as a larger N400 and a smaller LPC with broad distributions (as is shown in the scalp topographies in Fig. 4b).

\section{Discussion}

In the present study, we aimed to investigate the influence of emotional words on the semantic integration of subsequent neutral words. We manipulated the emotionality of the verbs and the semantic congruity between the following nouns and the contexts prior to the verbs. The ERP results showed that the semantically incongruent nouns elicited larger N400 and 
A ERP waveforms showing the emotionality effects.

F3

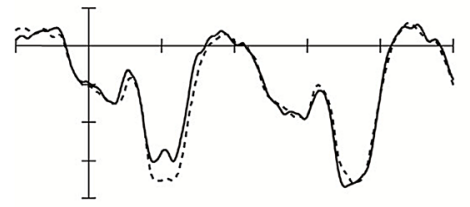

$\mathrm{C} 3$
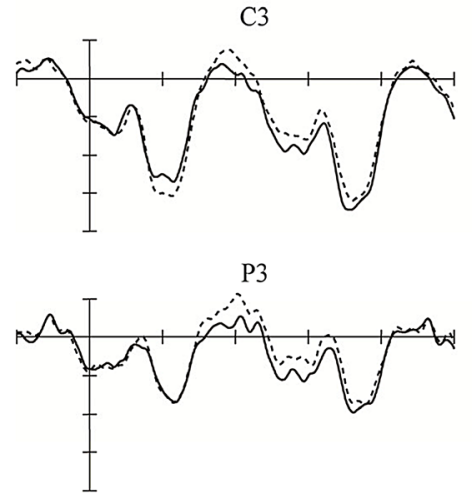

$\mathrm{B}$

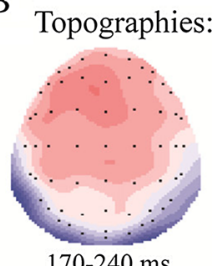

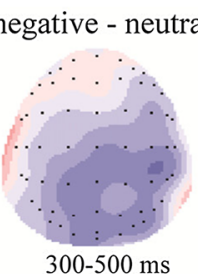
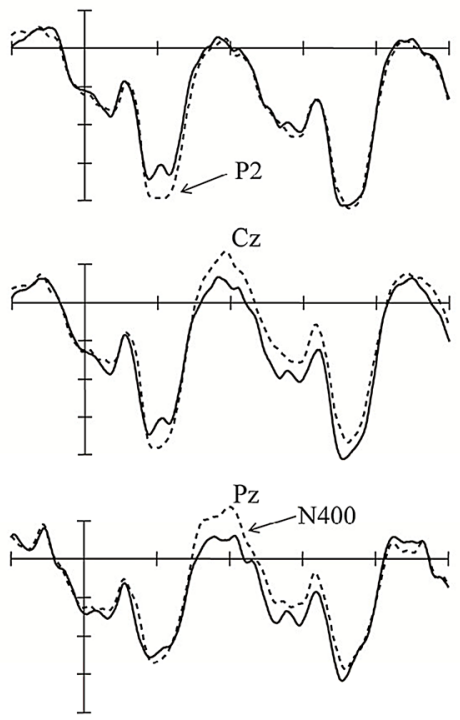

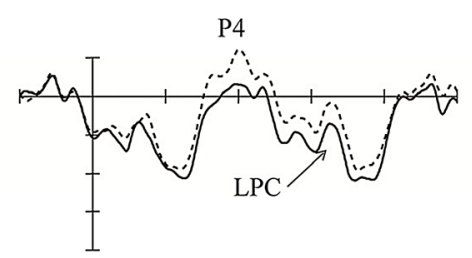

F4
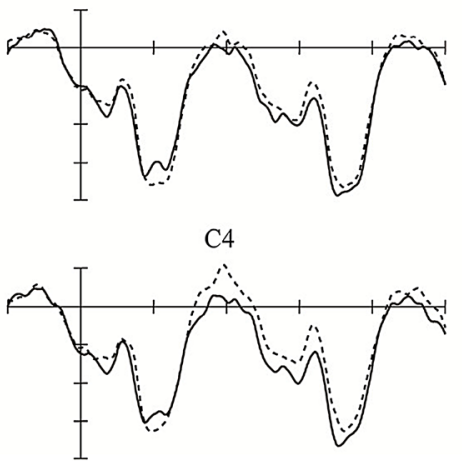

Fig. 4 Emotionality effects of the critical verbs. (a) Grand averaged waveforms evoked by the critical verbs at nine representative electrodes. The solid lines represent neutral verbs, and the dotted lines

P600 components than did the congruent nouns in the neutral contexts. However, only an N400 semantic congruity effect was observed in the negative contexts. Meanwhile, the negative verbs yielded a larger P2, a larger N400, and a smaller late positivity than did the neutral verbs.

\section{Emotionality modulation on semantic processing}

In the present study, the critical nouns were either semantically congruent or incongruent relative to the introductory contexts prior to the critical verbs. The semantically incongruent nouns elicited a larger N400 and a larger P600 than did the semantically congruent nouns in the neutral context. However, the P600 (but not the N400) semantic congruity effect may have been attenuated in the negative contexts. If this is a true effect, it would hold a number of implications for the dynamic influence of emotional words on the semantic integration of sentences. The N400 is a well-established component that relates to semantic analysis, with larger N400 amplitudes reflecting more effortful integration of incongruent words into the previous contexts (Kutas \& Federmeier, 2011). In the present study, the semantically incongruent nouns elicited larger

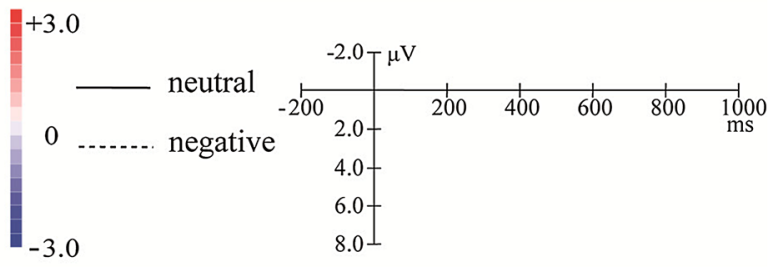

represent negative verbs. (b) Topographies showing the average amplitude voltage differences between the negative and neutral verbs

N400s than did the congruent nouns in both the neutral and negative contexts, suggesting that the incongruent words caused integration difficulty in both the neutral and negative contexts.

In addition to the $\mathrm{N} 400$ effect, the semantically incongruent nouns elicited larger P600s than did the congruent nouns when they followed the neutral verbs. The P600 characteristically started about $600 \mathrm{~ms}$ after the onset of the critical words and was mainly distributed over the posterior scalp region (Friederici, Pfeifer, \& Hahne, 1993; Hagoort, Brown, \& Groothusen, 1993; Osterhout \& Holcomb, 1992). The early view of the P600 effect in language studies associated it with syntactic processing difficulty (Kaan, Harris, Gibson, \& Holcomb, 2000). However, the P600 effect observed here should not be a reflection of syntactic processing, because we performed no syntactic manipulation in the present study. The P600 effect elicited by semantic incongruity has also been repeatedly reported in previous studies (e.g., Kuperberg et al., 2007; Nieuwland \& Van Berkum, 2005; Szewczyk \& Schriefers, 2011). Such semantic violations involved verbargument violations (Kuperberg, 2007) and hard-to-detect semantic violations (Brouwer, Fitz, \& Hoeks, 2012; Sanford, 
Leuthold, Bohan, \& Sanford, 2011). Szewczyk and Schriefers (2011) interpreted the P600 effect as a reflection of general reanalysis or a well-formedness check of the sentence. Following this view, the P600 effect observed in the present study indicates reanalysis of the semantically incongruent inputs.

Overall, the monophasic N400 effect in the negative context and the biphasic N400-P600 pattern in the neutral context revealed an influence of emotional words on semantic integration of the following words during sentence comprehension. In the present study, the semantic incongruities in the negative and neutral contexts were created using the same introductory sentential contexts, and they only differed in the emotionality of the preceding verbs. Therefore, the different ERP effects could only be attributed to the influence of the verbs. Behavioral and electrophysiological studies have revealed the privileged status of emotional words, compared with neutral words, during cognitive processes (for reviews, see Citron, 2012; Vuilleumier \& Huang, 2009). Emotional words automatically capture and hold attentional resources. According to the attention-narrowing hypothesis, the attentional resources occupied by emotional words could not be released immediately for further processing. In the context of semantic analysis, the lack of sufficient processing resources in the emotional condition led to impaired reanalysis of the semantically incongruent nouns. These results are in line with the attentional blink (AB) effect, which is an impairment effect of reduced report accuracy of a second target (T2) presented less than $500 \mathrm{~ms}$ after a first target (T1; Shapiro, Raymond, \& Arnell, 1994). The AB effect was larger when high-arousing emotional words served as the T1 (e.g., Mathewson et al., 2008), indicating that more attentional resources were occupied by preceding emotional information. The present study extends these findings by suggesting that the emotional words influenced the semantic reanalysis of their following neutral words. Overall, the present findings support the attention-narrowing hypothesis.

Nevertheless, it is interesting to note that the processing resources occupied by the preceding negative words only affected the reanalysis of the nouns, not their initial semantic analysis. This might be due to the emotional influence on the attentional resources being quite subtle, so that the effect was only apparent in a more flexible (task-dependent) component of the processing (i.e., the reanalysis of the nouns, as indicated by the P600 effect), but not in an indispensable component of the processing (i.e., the initial semantic analysis of the nouns, as indicated by the N400 effect). The automaticity of the N400 has been found in various studies (for a review, see Kutas \& Federmeier, 2011). For instance, similar N400 effects were observed even when some secondary task was imposed in addition to the primary comprehension task (Connolly, Stewart, \& Phillips, 1990). Also, Luck, Vogel, and Shapiro (1996) reported an N400 effect when T2 words were semantically related to the given contextual words in an $\mathrm{AB}$ paradigm, suggesting that the $\mathrm{N} 400$ effect can be elicited even in the absence of awareness. Similarly, the N400 effect in response to semantic priming has also been found during sleep (for a review, see Ibáñez, Martin, Hurtado, \& López, 2009) and in amnesia (Olichney et al., 2000). Therefore, the automaticity of the N400 might explain the lack of emotional modulation of the N400 component. In contrast, the P600 effect in response to semantic congruity was shown to be sensitive to the task requirements (and thus to the allocation of processing resources). For instance, Geyer, Holcomb, Kuperberg, and Perlmutter (2006) reported both N400 and P600 effects in response to semantic congruity when detailed semantic analysis was required, but only an N400 effect when no such requirement was made. The task modulation found in this study suggests that the P600 effect is more flexible and susceptible to attentional modulation. In the present study, the semantically incongruent nouns elicited a larger N400 than did the congruent nouns in both the negative and neutral contexts, but a larger P600 only in the neutral context. The N400 and P600 effects in the neutral context suggest that sufficient attentional resources were available for both the initial analysis and reanalysis of semantic processing. However, the absence of a P600 effect in the negative context suggests that only the semantic reanalysis was affected under the limited attentional resources allocated to the neutral words following emotional words.

As we reviewed in the introduction, several studies have investigated the influence of emotion on the semantic integration of neutral words in sentence- or discourse-reading studies (e.g., Jiménez-Ortega et al., 2012; Moreno \& Vázquez, 2011). The results observed in the negative context in the present study are consistent with the study of Moreno and Vázquez, in which the violating words also elicited a larger N400 within emotionally biased sentence frames. However, JiménezOrtega et al. found that semantic violations elicited both N400 and P600 effects in sentences following both emotional and neutral paragraphs. The discrepancies of the results could be explained by the distance between the emotional and violating information. In the study of Jiménez-Ortega et al., following an emotional or neutral paragraph, a noun-adjective semantic incompatibility (semantic violation) occurred in a neutral sentence that had a determiner-noun-adjective-verb structure. The distance between the emotion induced by the preceeding paragraph and the semantic violation was larger than we provided in the present study. Therefore, we conclude that the emotional modulation from preceding words was stronger than that induced by paragraphs in the study by Jiménez-Ortega et al. This might be attributed to the direct connection between the emotional verbs (emotion induction) and the neutral nouns (semantic manipulation) in the same argument structure. Our results are in line with those of our previous study (Ding et al., 2015), in which we examined the 
influence of emotional verbs on the orthographic analysis of following nouns during sentence processing. We found that orthographic violations in the nouns elicited P2 and N400 effects when they followed neutral verbs, but an LPC effect when they followed emotional verbs. The results indicated delayed detection of the orthographic violation due to a lack of sufficient processing resources allocated to the nouns following the emotional verbs. In the present study, the lack of the P600 effect in response to the semantic congruity in the negative context suggests an absence of semantic reanalysis in the negative context. Therefore, both studies revealed an impairment effect of emotional words on the processing of their following neutral words. Overall, our present study further demonstrates the dynamic influence of emotional words on the semantic integration of words during sentence comprehension.

\section{Emotional word processing in sentences}

In the present study, the negative verbs elicited a larger P2 over anterior regions than did the neutral verbs. Such P2 effect has also been reported in previous studies (Ding et al., 2015; Wang, Bastiaansen, et al., 2013). The larger P2 indicates automatic attention orientation to emotional stimuli and conscious processing of affective content (Citron, 2012). Therefore, the emotionality enhances the perceptual processing of emotional words during the early stages of meaning encoding.

Following the P2 effect, the negative verbs elicited a larger N400 than did the neutral verbs. Such an N400 effect has also been found in several other studies in which the words were embedded in neutral contexts (De Pascalis, Arwari, D'Antuono, \& Cacace, 2009; Ding et al., 2015; Holt et al., 2009). These results indicate either more attentional resources allocated to the emotional words or different neural representations between the emotional and neutral words. However, Martín-Loeches et al. (2012) and Wang, Bastiaansen, et al. (2013) reported no difference in the N400s between negative and neutral words, but smaller N400s for positive words in the neutral sentence contexts. The discrepancies between the present study and the previous studies might be attributed to the different stimuli used in different studies (e.g., Martín-Loeches et al., 2012, used Spanish; Wang, Bastiaansen, et al., 2013, used Dutch; and in the present study we used Chinese stimuli).

Moreover, unlike in most of the previous studies, in which a larger LPC was found for emotional than for neutral words (see the reviews by Citron, 2012; Hajcak et al., 2012; Kissler, Assadollahi, \& Herbert, 2006), the emotional verbs elicited a smaller LPC than did the neutral verbs in the present study. The larger LPC elicited by emotional words embedded in sentences has been taken as a reflection of reallocation of attentional resources toward emotional information for emotional evaluation (Hajcak et al., 2012). Unlike in previous studies, we found that the LPC for the negative verbs was smaller than for the neutral verbs. One possible explanation is that the LPC for negative verbs fell in the early time windows of the following nouns, so that early processing of the nouns might have affected the ERPs elicited by the previous verbs. However, given that the negative and neutral verbs were followed by the same nouns, it is very unlikely that the processing of the following nouns caused the LPC difference between the negative and neutral verbs. On the basis of the similar scalp distributions between the LPC effect and the preceding N400 effect, we tentatively took the LPC effect as a continuation of the N400 effect (Luck, 2014). Such a longlasting N400 effect has been taken as a reflection of more attentional resources being allocated to prominent stimuli (Li, Hagoort, \& Yang, 2008; Li \& Yang, 2013). Therefore, the long-lasting N400 effect in response to the emotionality of words reflects the greater allocation of attentional resources to negative than to neutral words.

\section{Conclusions}

The semantic incongruity between object nouns and their preceding sentence contexts elicited an N400 and a P600 effect when the incongruity followed neutral verbs. However, the P600 (but not the N400) semantic congruity effect may have been attenuated when it followed emotional verbs. The results suggest that the emotional words impaired the reanalysis of the following neutral words during sentence comprehension because more attentional resources were occupied by the emotional words. The results are in line with the attention-narrowing hypothesis. In addition, the emotional verbs elicited a larger P2 and a larger, long-lasting N400 than the neutral verbs. These ERP effects indicate that emotional words are processed differently from neutral words at both perceptual and semantic levels. To conclude, emotional words have a dynamic influence on the semantic integration of words during language comprehension, further demonstrating the influence of emotion on cognition.

Author note This research was supported by awards from the National Natural Science Foundation of China to Y.Y. (Grant No. 31070989) and to L.W. (Grant No. 31200849).

\section{References}

Bayer, M., Sommer, W., \& Schacht, A. (2012). P1 and beyond: Functional separation of multiple emotion effects in word recognition. Psychophysiology, 49, 959-969. doi:10.1111/j.1469-8986. 2012.01381.x

Blair, K., Smith, B., Mitchell, D., Morton, J., Vythilingam, M., Pessoa, L., \& Drevets, W. (2007). Modulation of emotion by cognition and cognition by emotion. NeuroImage, 35, 430-440. doi:10.1016/j. neuroimage.2006.11.048 
Brierley, B., Medford, N., Shaw, P., \& David, A. S. (2007). Emotional memory for words: Separating content and context. Cognition and Emotion, 21, 495-521. doi:10.1080/02699930600684963

Briesemeister, B. B., Kuchinke, L., \& Jacobs, A. M. (2014). Emotion word recognition: Discrete information effects first, continuous later? Brain Research, 1564, 62-71. doi:10.1016/j.brainres.2014.03. 045

Brouwer, H., Fitz, H., \& Hoeks, J. (2012). Getting real about semantic illusions: Rethinking the functional role of the P600 in language comprehension. Brain Research, 1446, 127-143. doi:10.1016/j. brainres.2012.01.055

Brown, C., \& Hagoort, P. (1993). The processing nature of the N400: Evidence from masked priming. Journal of Cognitive Neuroscience, 5, 34 44. doi:10.1162/jocn.1993.5.1.34

Cai, Q., \& Brysbaert, M. (2010). SUBTLEX-CH: Chinese word and character frequencies based on film subtitles. PLOS ONE, 5, e10729. doi:10.1371/journal.pone.0010729

Carretié, L., Hinojosa, J. A., Albert, J., López-Martín, S., de la Gándara, B., Igoa, J. M., \& Sotillo, M. (2008). Modulation of ongoing cognitive processes by emotionally intense words. Psychophysiology, 45, 188-196. doi:10.1111/j.1469-8986.2007.00617.x

Christianson, S.-Å. (1992). Emotional stress and eyewitness memory: A critical review. Psychological Bulletin, 112, 284-309. doi:10.1037/ 0033-2909.112.2.284

Citron, F. M. (2012). Neural correlates of written emotion word processing: A review of recent electrophysiological and hemodynamic neuroimaging studies. Brain and Language, 122, 211-226. doi:10. 1016/j.bandl.2011.12.007

Compumedics Neuroscan. (2003). Offline analysis of acquired data (SCAN 4.3-Vol. II, EDIT 4.3) [Software manual]. El Paso, TX: Author.

Connolly, J. F., Stewart, S., \& Phillips, N. (1990). The effects of processing requirements on neurophysiological responses to spoken sentences. Brain and Language, 39, 302-318. doi:10.1016/0093934X(90)90016-A

Craik, F. I. M., \& Lockhart, R. S. (1972). Levels of processing: A framework for memory research. Journal of Verbal Learning and Verbal Behavior, 11, 671-684. doi:10.1016/S0022-537180001-X

Craik, F. I. M., \& Tulving, E. (1975). Depth of processing and the retention of words in episodic memory. Journal of Experimental Psychology: General, 104, 268-294. doi:10.1037/0096-3445.104. 3.268

Dambacher, M., Dimigen, O., Braun, M., Wille, K., Jacobs, A. M., \& Kliegl, R. (2012). Stimulus onset asynchrony and the timeline of word recognition: Event-related potentials during sentence reading. Neuropsychologia, 50, 1852-1870. doi:10.1016/j. neuropsychologia.2012.04.011

De Pascalis, V., Arwari, B., D’Antuono, L., \& Cacace, I. (2009). Impulsivity and semantic/emotional processing: An examination of the N400 wave. Clinical Neurophysiology, 120, 85-92. doi:10. 1016/j.clinph.2008.10.008

Delaney-Busch, N., \& Kuperberg, G. (2013). Friendly drug-dealers and terrifying puppies: Affective primacy can attenuate the N400 effect in emotional discourse contexts. Cognitive, Affective, \& Behavioral Neuroscience, 13, 473-490. doi:10.3758/s13415-013-0159-5

Dien, J. (2009). The neurocognitive basis of reading single words as seen through early latency ERPs: A model of converging pathways. Biological Psychology, 80, 10-22. doi:10.1016/j.biopsycho.2008. 04.013

Ding, J., Wang, L., \& Yang, Y. (2015). The dynamic influence of emotional words on sentence processing. Cognitive, Affective, \& Behavioral Neuroscience, 15, 55-68. doi:10.3758/s13415-0140315-6

Easterbrook, J. A. (1959). The effect of emotion on cue utilization and the organization of behavior. Psychological Review, 66, 183-201. doi: 10.1037/h0047707
Fischler, I., \& Bradley, M. (2006). Event-related potential studies of language and emotion: words, phrases, and task effects. Progress in Brain Research, 156, 185-204. doi:10.1016/S0079-6123(06) 56009-1

Friederici, A. D., Pfeifer, E., \& Hahne, A. (1993). Event-related brain potentials during natural speech processing: Effects of semantic, morphological and syntactic violations. Cognitive Brain Research, 1, 183-192. doi:10.1016/0926-6410(93)90026-2

Fritsch, N., \& Kuchinke, L. (2013). Acquired affective associations induce emotion effects in word recognition: An ERP study. Brain and Language, 124, 75-83. doi:10.1016/j.bandl.2012.12.001

Geyer, A., Holcomb, P., Kuperberg, G., \& Perlmutter, N. (2006). Plausibility and sentence comprehension: An ERP study. Cognitive Neuroscience Supplement, 2006, Abstract 19.

Gray, J. R., Braver, T. S., \& Raichle, M. E. (2002). Integration of emotion and cognition in the lateral prefrontal cortex. Proceedings of the National Academy of Sciences, 99, 4115-4120. doi:10.1073/pnas. 062381899

Greenhouse, S. W., \& Geisser, S. (1959). On methods in the analysis of profile data. Psychometrika, 24, 95-112. doi:10.1007/BF02289823

Guillet, R., \& Arndt, J. (2009). Taboo words: The effect of emotion on memory for peripheral information. Memory \& Cognition, 37, 866879. doi:10.3758/MC.37.6.866

Hadley, C. B., \& MacKay, D. G. (2006). Does emotion help or hinder immediate memory? Arousal versus priority-binding mechanisms. Journal of Experimental Psychology: Learning, Memory, and Cognition, 32, 79-88. doi:10.1037/0278-7393.32.1.79

Hagoort, P., Brown, C., \& Groothusen, J. (1993). The syntactic positive shift (SPS) as an ERP measure of syntactic processing. Language \& Cognitive Processes, 8, 439-483. doi:10.1080/ 01690969308407585

Hajcak, G., Weinberg, A., MacNamara, A., \& Foti, D. (2012). ERPs and the study of emotion. In S. J. Luck \& E. S. Kappenman (Eds.), Oxford handbook of event-related potential components (pp. 441474). New York, NY: Oxford University Press.

Herbert, C., Junghöfer, M., \& Kissler, J. (2008). Event related potentials to emotional adjectives during reading. Psychophysiology, 45, 487498. doi:10.1111/j.1469-8986.2007.00638.x

Herbert, C., Kissler, J., Junghöfer, M., Peyk, P., \& Rockstroh, B. (2006). Processing of emotional adjectives: Evidence from startle EMG and ERPs. Psychophysiology, 43, 197-206. doi:10.1111/j.1469-8986. 2006.00385.x

Hinojosa, J. A., Méndez-Bértolo, C., \& Pozo, M. A. (2010). Looking at emotional words is not the same as reading emotional words: Behavioral and neural correlates. Psychophysiology, 47, 748-757. doi:10.1111/j.1469-8986.2010.00982.x

Hinojosa, J. A., Méndez-Bértolo, C., \& Pozo, M. A. (2012). High arousal words influence subsequent processing of neutral information: Evidence from event-related potentials. International Journal of Psychophysiology, 86, 143-151. doi:10.1016/j.ijpsycho.2012.06. 001

Holt, D. J., Lynn, S. K., \& Kuperberg, G. R. (2009). Neurophysiological correlates of comprehending emotional meaning in context. Journal of Cognitive Neuroscience, 21, 2245-2262. doi:10.1162/jocn.2008. 21151

Ibáñez, A. M., Martin, R. S., Hurtado, E., \& López, V. (2009). ERPs studies of cognitive processing during sleep. International Journal of Psychology, 44, 290-304. doi:10.1080/00207590802194234

Jiménez-Ortega, L., Martín-Loeches, M., Casado, P., Sel, A., Fondevila, S., de Tejada, P. H., \& Sommer, W. (2012). How the emotional content of discourse affects language comprehension. PLOS ONE, 7, e33718. doi:10.1371/journal.pone.0033718

Kaan, E., Harris, A., Gibson, E., \& Holcomb, P. (2000). The P600 as an index of syntactic integration difficulty. Language \& Cognitive Processes, 15, 159-201. doi:10.1080/016909600386084 
Kanske, P., \& Kotz, S. A. (2007). Concreteness in emotional words: ERP evidence from a hemifield study. Brain Research, 1148, 138-148. doi:10.1016/j.brainres.2007.02.044

Kissler, J., Assadollahi, R., \& Herbert, C. (2006). Emotional and semantic networks in visual word processing: Insights from ERP studies. Progress in Brain Research, 156, 147-183. doi:10.1016/S00796123(06)56008-X

Kissler, J., \& Herbert, C. (2013). Emotion, etmnooi, or emitoon? Faster lexical access to emotional than to neutral words during reading. Biological Psychology, 92, 464-479. doi:10.1016/j.biopsycho. 2012.09.004

Kissler, J., Herbert, C., Winkler, I., \& Junghöfer, M. (2009). Emotion and attention in visual word processing - An ERP study. Biological Psychology, 80, 75-83. doi:10.1016/j.biopsycho.2008.03.004

Kuchinke, L., Krause, B., Fritsch, N., \& Briesemeister, B. B. (2014). A familiar font drives early emotional effects in word recognition. Brain and Language, 137, 142-147. doi:10.1016/j.band1.2014.08. 007

Kuperberg, G. R. (2007). Neural mechanisms of language comprehension: Challenges to syntax. Brain Research, 1146, 23-49. doi:10. 1016/j.brainres.2006.12.063

Kuperberg, G. R., Kreher, D. A., Sitnikova, T., Caplan, D. N., \& Holcomb, P. J. (2007). The role of animacy and thematic relationships in processing active English sentences: Evidence from eventrelated potentials. Brain and Language, 100, 223-237. doi:10.1016/ j.bandl.2005.12.006

Kutas, M., \& Federmeier, K. D. (2011). Thirty years and counting: Finding meaning in the N400 component of the event-related brain potential (ERP). Annual Review of Psychology, 62, 621-647. doi:10. 1146/annurev.psych.093008.131123

LeDoux, J. (2003). The emotional brain, fear, and the amygdala. Cellular and Molecular Neurobiology, 23, 727-738. doi:10.1023/ A:1025048802629

Levens, S. M., \& Phelps, E. A. (2008). Emotion processing effects on interference resolution in working memory. Emotion, 8, 267-280. doi:10.1037/1528-3542.8.2.267

Leventhal, H., \& Scherer, K. (1987). The relationship of emotion to cognition: A functional approach to a semantic controversy. Cognition and Emotion, 1, 3-28. doi:10.1080/02699938708408361

Li, X., Hagoort, P., \& Yang, Y. (2008). Event-related potential evidence on the influence of accentuation in spoken discourse comprehension in Chinese. Journal of Cognitive Neuroscience, 20, 906-915. doi: 10.1162/jocn.2008.20512

Li, X., \& Yang, Y. (2013). How long-term memory and accentuation interact during spoken language comprehension. Neuropsychologia, 51, 967-978. doi:10.1016/j.neuropsychologia. 2012.12.016

Luck, S. J. (2014). An introduction to the event-related potential technique (2nd ed.). Cambridge, MA: MIT Press.

Luck, S. J., Vogel, E. K., \& Shapiro, K. L. (1996). Word meanings can be accessed but not reported during the attentional blink. Nature, 383, 616-618. doi:10.1038/383616a0

Lyons, W. (2005). The philosophy of cognition and emotion. In T. Dalgleish \& M. J. Power (Eds.), Handbook of cognition and emotion (pp. 21-44). Chichester, UK: Wiley.

MacKay, D. G., Shafto, M., Taylor, J. K., Marian, D. E., Abrams, L., \& Dyer, J. R. (2004). Relations between emotion, memory, and attention: Evidence from taboo Stroop, lexical decision, and immediate memory tasks. Memory \& Cognition, 32, 474-488. doi:10.3758/ BF03195840

Martín-Loeches, M., Fernández, A., Schacht, A., Sommer, W., Casado, P., Jiménez-Ortega, L., \& Fondevila, S. (2012). The influence of emotional words on sentence processing: Electrophysiological and behavioral evidence. Neuropsychologia, 50, 3262-3272. doi:10. 1016/j.neuropsychologia.2012.09.010
Mathewson, K. J., Arnell, K. M., \& Mansfield, C. A. (2008). Capturing and holding attention: The impact of emotional words in rapid serial visual presentation. Memory \& Cognition, 36, 182-200. doi:10. 3758/MC.36.1.182

Moreno, E. M., \& Vázquez, C. (2011). Will the glass be half full or half empty? Brain potentials and emotional expectations. Biological Psychology, 88, 131-140. doi:10.1016/j.biopsycho.2011.07.003

Nieuwland, M. S., \& Van Berkum, J. J. (2005). Testing the limits of the semantic illusion phenomenon: ERPs reveal temporary semantic change deafness in discourse comprehension. Cognitive Brain Research, 24, 691-701. doi:10.1016/j.cogbrainres.2005.04.003

Ochsner, K. N., \& Phelps, E. (2007). Emerging perspectives on emotioncognition interactions. Trends in Cognitive Sciences, 11, 317-318. doi:10.1016/j.tics.2007.06.008

Olichney, J. M., Van Petten, C., Paller, K. A., Salmon, D. P., Iragui, V. J., \& Kutas, M. (2000). Word repetition in amnesia: Electrophysiological measures of impaired and spared memory. Brain, 123, 1948-1963. doi:10.1093/brain/123.9.1948

Osterhout, L., \& Holcomb, P. J. (1992). Event-related brain potentials elicited by syntactic anomaly. Journal of Memory and Language, 31, 785-806. doi:10.1016/0749-596X(92)90039-Z

Pessoa, L. (2008). On the relationship between emotion and cognition. Nature Reviews Neuroscience, 9, 148-158. doi:10.1038/nrn2317

Phelps, E. A. (2006). Emotion and cognition: Insights from studies of the human amygdala. Annual Review of Psychology, 57, 27-53. doi:10. 1146/annurev.psych.56.091103.070234

Sanford, A. J., Leuthold, H., Bohan, J., \& Sanford, A. J. (2011). Anomalies at the borderline of awareness: An ERP study. Journal of Cognitive Neuroscience, 23, 514-523. doi:10.1162/jocn.2009. 21370

Sass, S. M., Heller, W., Stewart, J. L., Silton, R. L., Edgar, J. C., Fisher, J. E., \& Miller, G. A. (2010). Time course of attentional bias in anxiety: Emotion and gender specificity. Psychophysiology, 47, 247259. doi:10.1111/j.1469-8986.2009.00926.x

Schacht, A., \& Sommer, W. (2009). Emotions in word and face processing: Early and late cortical responses. Brain and Cognition, 69, 538550. doi:10.1016/j.bandc.2008.11.005

Scott, G. G., O'Donnell, P. J., Leuthold, H., \& Sereno, S. C. (2009). Early emotion word processing: Evidence from event-related potentials. Biological Psychology, 80, 95-104. doi:10.1016/j.biopsycho.2008. 03.010

Semlitsch, H. V., Anderer, P., Schuster, P., \& Presslich, O. (1986). A solution for reliable and valid reduction of ocular artifacts, applied to the P300 ERP. Psychophysiology, 23, 695-703. doi:10.1111/j. 1469-8986.1986.tb00696.x

Shapiro, K. L., Raymond, J. E., \& Arnell, K. M. (1994). Attention to visual pattern information produces the attentional blink in rapid serial visual presentation. Journal of Experimental Psychology: Human Perception and Performance, 20, 357-371. doi:10.1037/ 0096-1523.20.2.357

Szewczyk, J. M., \& Schriefers, H. (2011). Is animacy special? ERP correlates of semantic violations and animacy violations in sentence processing. Brain Research, 1368, 208-221. doi:10.1016/j. brainres.2010.10.070

Vissers, C. T. W., Chwilla, D. J., \& Kolk, H. H. (2006). Monitoring in language perception: The effect of misspellings of words in highly constrained sentences. Brain Research, 1106, 150-163. doi:10. 1016/j.brainres.2006.05.012

Vuilleumier, P. (2005). How brains beware: Neural mechanisms of emotional attention. Trends in Cognitive Sciences, 9, 585-594. doi:10. 1016/j.tics.2005.10.011

Vuilleumier, P., \& Huang, Y.-M. (2009). Emotional attention uncovering the mechanisms of affective biases in perception. Current Directions in Psychological Science, 18, 148-152. doi:10.1111/j.1467-8721. 2009.01626.x 
Wang, L., \& Bastiaansen, M. (2014). Oscillatory brain dynamics associated with the automatic processing of emotion in words. Brain and Language, 137, 120-129. doi:10.1016/j.bandl.2014.07.011

Wang, L., Bastiaansen, M., Yang, Y., \& Hagoort, P. (2013a). ERP evidence on the interaction between information structure and emotional salience of words. Cognitive, Affective, \& Behavioral Neuroscience, 13, 297-310. doi:10.3758/s13415-012-0146-2
Wang, L., Zhu, Z., Bastiaansen, M., Hagoort, P., \& Yang, Y. (2013b). Recognizing the emotional valence of names: An ERP study. Brain and Language, 125, 118-127. doi:10.1016/j.bandl.2013.01.006

Zhang, D., He, W., Wang, T., Luo, W., Zhu, X., Gu, R., \& Luo, Y.-J. (2014). Three stages of emotional word processing: An ERP study with rapid serial visual presentation. Social Cognitive and Affective Neuroscience, 9, 1897-1903. doi:10.1093/scan/nst188 